\title{
Scaling Up Tobacco Cessation within TB Programmes: Findings from a Multi- Country, Mixed-Methods, Implementation Study.
}

Helen Elsey ( $\nabla$ helen.elsey@york.ac.uk)

University of York https://orcid.org/0000-0003-4724-0581

Zunayed Al Azdi

ARK Foundation

Shophika Regmi

HERD: Health Research and Social Development Forum

Sushil Baral

HERD: Health Research and Social Development Forum

Razia Fatima

Government of Pakistan

Fariza Feroze

Arkin Foundation: Arkin

Rumana Huque

Arkin Foundation: Arkin

Jiban Karki

University of Leeds

Dost Mohammad Khan

Government of Pakistan

Amina Khan

The Initiative

Zohaib Khan

Khyber Medical University

Jinshuo Li

University of York Department of Health Sciences

Maryam Noor

The Initiative

Abriti Arjyal

HERD: Health Research and Social Development Forum

Prabin Shrestha

HERD: Health Research and Social Development Forum

Safat Ullah

Khyber Medical University

Kamran Siddiqi

University of York Department of Health Sciences

\section{Research}

Keywords: scale-up, tuberculosis, tobacco cessation, implementation research, ExpandNet Steps for Scale-Up

Posted Date: October 12th, 2021

DOI: https://doi.org/10.21203/rs.3.rs-927139/v1

License: (c) (i) This work is licensed under a Creative Commons Attribution 4.0 International License. Read Full License

Version of Record: A version of this preprint was published at Health Research Policy and Systems on April 18th, 2022. See the published version at https://doi.org/10.1186/s12961-022-00842-1. 


\section{Abstract}

Background: Brief behavioural support can effectively help TB patients to quit smoking and improve their outcomes. In collaboration with TB programmes in Bangladesh, Nepal and Pakistan, we evaluated implementation and scale-up of cessation support using four strategies: i) brief tobacco cessation intervention ii) integration of tobacco cessation within routine training iii) inclusion of tobacco indicators in routine records and iv) embedding research within TB programmes.

Methods: We used mixed methods of observation, interviews and routine data within WHO's ExpandNet framework for scale-up. We aimed to understand the extent of, and strategies which facilitated vertical scale-up (institutionalisation) within 59 health facility learning sites in Pakistan, 18 in Nepal and 15 in Bangladesh and horizontal scale-up (increased coverage beyond learning sites). We observed training and surveyed 169 TB health workers to measure changes in their confidence to deliver cessation. Routine TB data from the learning sites was analysed to assess delivery of the intervention and use of TB forms revised to report smoking status and cessation support provided. A purposive sample of TB health workers, managers and policymakers were interviewed (Bangladesh: $n=12$; Nepal $n=13$; Pakistan $n=19 ;$ ). Costs of scale-up were estimated using activity-based cost-analysis.

Results: Routine data indicated health workers in learning sites asked all TB patients about tobacco use and offered them cessation support. Qualitative data showed use of intervention materials, often with adaptation and partial implementation in busy clinics. Short (1-2 hours) training integrated within existing programmes increased mean confidence to deliver cessation by $17 \%$ ( $95 \% \mathrm{Cl}$ : $14 \%$ to $20 \%)$. A focus on health system changes (reporting, training, supervision) facilitated vertical scale-up. Dissemination of materials beyond learning sites and changes to national reporting forms and training indicated horizontal scale-up. Embedding research within TB health systems was crucial for horizontal scale-up and required dynamic use of tactics e.g. alliancebuilding, engagement in wider policy process, use of insider-researchers, and deep understanding of health system actors and processes.

Conclusions: System-level changes within TB programmes may enable routine delivery of cessation support to TB patients. These strategies are inexpensive and, with concerted efforts from TB programmes and donors, tobacco cessation can be institutionalised at-scale.

\section{Introduction}

A detrimental relationship between tuberculosis (TB) and tobacco use is well established. Smoking is responsible for $16 \%$ of the global TB disease burden by adversely affecting TB outcomes (1-5). Brief behaviour support for tobacco cessation, delivered by health professionals as part of routine TB care has been found to be effective in helping patients to quit $(6,7)$ and improving TB outcomes (8). Despite evidence of its effectiveness, this simple and affordable intervention has yet to be implemented and scaled-up within National TB Programmes (NTPs) in high-TB burden countries such as Bangladesh, Nepal and Pakistan (9). This is consistent with the global picture where only $32 \%$ of the general population are able to access cessation services (10). This is despite the high proportion of current tobacco smokers in all three countries: $41.4 \%$ of males and $1.4 \%$ of females in Bangladesh; $33.7 \%$ of males and $8.8 \%$ of females in Nepal; $31 \%$ of males and $2.8 \%$ of females in Pakistan (11). In addition to high tobacco prevalence, all three countries suffer a high burden of TB incidence: 221 per 100,000 in Bangladesh, 2018 (12), 245 per 100,000 in Nepal, 2020 (13) and 265 per 100,000 in Pakistan, 2018 (12).

In Bangladesh, Nepal and Pakistan, despite increasing recognition by policy-makers of the need for tobacco cessation, health system components to support cessation such as recording and reporting, health worker skill level and limited time per patient restrict its delivery $(14,15)(14,16)$. Within pragmatic trials, where these health system barriers can be addressed in the short term, high quit rates have been achieved. The ASSIST randomised controlled trial (RCT) in Pakistan found $41.0 \%(\mathrm{Cl}, 37.1-45.0 \%)$ of those with suspected TB were able to quit at six months verified bio-chemically following brief behavioural support, (6).

Overcoming health system barriers to allow scale-up of tobacco cessation within routine TB programmes has the potential to benefit patients' recovery from TB, their own future health outcomes across multiple non-communicable diseases as well as reducing risks of second-hand smoking and risk of TB transmission among those around them (17). Given the health systems challenges identified, this paper presents an implementation research study to understand what steps can be taken to implement 'systems-orientated scale-up' (18) of brief behaviour support within routine TB care in Bangladesh, Nepal and Pakistan.

There has been an increased focus on developing and using frameworks to support systematic scale-up of health interventions (19-22). ExpandNet's 'Nine steps for developing a scaling up strategy' provides a useful framework to both plan and analyse the process (20) and defines scale-up as: "deliberate efforts to increase the impact of successfully tested health innovations so as to benefit more people and to foster policy and programme development on a lasting basis." (ExpandNet 2010 p. 9). ExpandNet distinguishes between vertical scale-up, i.e. institutionalisation of the intervention and horizontal scale-up, i.e. increased coverage. We draw on ExpandNet's steps and existing evidence of what works when scaling-up public health interventions (19, 21, 23) to assess vertical and horizontal scale-up of tobacco cessation within Bangladesh, Nepal and Pakistan. We worked with NTPs to identify learning sites in each country and to prioritise health system changes needed to support and facilitate the scale-up of tobacco cessation within routine services. Four strategies were identified, implemented and evaluated in each country and are described below.

\section{Strategies for Scale-up}

Strategy 1: A simple and adaptable intervention: Step 1 of the ExpandNet framework (see table 8) focuses on intervention adaptation to ensure it is amenable to scale-up. Through a process of qualitative interviews, focus groups and workshops with TB managers, patients and health workers reported elsewhere (9), content of the intervention used in the ASSIST trial (6) was condensed to less than 10 minutes consultation whilst retaining core behaviour change techniques (BCTs) (24) identified as effective in the trial (6). TB health workers preference for a single resource that covered TB treatment messages, 
information on keeping healthy (diet, rest, exercise) and tobacco cessation was adopted (25). The components of the final simplified intervention are detailed in Table 1 below. 


Materials
Flipbook. for use during consultations
with all TB patients following diagnosis
and at any point during the 6-months of
TB treatment to reinforce messages and
support quit attempts.

Leaflet: for TB patients, their carers and family members

\section{Content}

Eight pages with photo pages facing patients and text facing health professionals. One version with photos targeting male patients and one version with photos targeting female patients: the first 5 pages include key messages on TB management and the final 3 pages have messages of tobacco (cigarettes and smokeless).

Using photos and illustrations and simple text highlighting the consequences of tobacco use (cigarettes and smokeless), link with TB, benefits of quitting and how to deal with side effects of quitting.

Two posters: for use within TB clinic waiting areas

One presents health benefits of quitting (general not TB specific) and one advertising the cessation service.

A health worker quide: to be used in conjunction with the flip book, leaflet and posters.

Providing the evidence behind the key messages, tips for adaptation and strategies for building rapport and good communication with both male and female patients.
Messages and BCT taxonomy code (24)

TB messages:

i) It is very likely that your TB will be cured if you take your medicines as instructed.

ii) Keep taking medicines regularly.

iii) Come for scheduled appointments, your health worker is here to support you.

iv) Understanding how TB spreads

v) Importance of social support

vi) Adopt a healthy diet and lifestyle, including quitting tobacco.

Cessation messages

i) Abrupt cessation: set a quit date and then, 'not a puff'.

ii) How to deal with side effects.

iii) Identifying triggers and alternative strategies.

iv) Consequences of tobacco use (cigarettes and smokeless) on TB, long-term health and finances.

v) Dangers of second-hand smoke.

Behaviour Change Techniques

i) Goal setting (1.1)

ii) Reducing negative emotions(1.2)

iii) Action planning(1.4)

iv) Prompting social support $(3.1,3.2,3.3)$,

v) Instructions on performing behaviours (4.1),

vi) Information on health and emotional consequences $(5.1,5.6)$

vii)Habit formation (8.3)

viii) Comparative imagining of future outcomes (9.3)

ix) Reducing negative emotions (11.2)

$x)$ Reducing exposure to cues for behaviour (12.3)

xi) Build rapport, being an active listener

All training and intervention materials are freely available in Urdu, Bengali, Nepalese and English from the TB and Tobacco website: https://tbandtobacco.org/ 


\begin{tabular}{|c|c|c|}
\hline Materials & Content & $\begin{array}{l}\text { Messages and BCT } \\
\text { taxonomy code (24) }\end{array}$ \\
\hline \multirow[t]{2}{*}{$\begin{array}{l}\text { Training of Trainers (ToT): half day } \\
\text { programme }\end{array}$} & $\begin{array}{l}\text { Introducing the intervention, key messages and underlying evidence. How to } \\
\text { deliver the messages and support TB health workers to deliver. }\end{array}$ & \\
\hline & $\begin{array}{l}\text { Includes a country-specific } 10 \text { minute video modelling how to ask about } \\
\text { tobacco use, advise and support patients to quit. }\end{array}$ & \\
\hline $\begin{array}{l}\text { Training session: two hour training } \\
\text { session for TB health workers delivered } \\
\text { by trainers following the ToT above. }\end{array}$ & $\begin{array}{l}\text { Introducing the intervention, and key cessation messages and how to } \\
\text { complete the tobacco columns in the recording forms. Including the } 10 \\
\text { minute video above. }\end{array}$ & $\begin{array}{l}\text { By delivering these key } \\
\text { messages using simple } \\
\text { BCTs, TB health workers } \\
\text { help their patients to quit } \\
\text { as part of routine care. }\end{array}$ \\
\hline $\begin{array}{l}\text { Awareness raising video: for TB } \\
\text { programme managers and policy-makers. }\end{array}$ & $\begin{array}{l}3 \text { minute video explaining the link between TB and Tobacco and the need to } \\
\text { include tobacco cessation support for TB patients. }\end{array}$ & $\begin{array}{l}\text { Inclusion of tobacco } \\
\text { cessation within the TB } \\
\text { programme is feasible and } \\
\text { can improve TB outcomes. }\end{array}$ \\
\hline
\end{tabular}

Strategy 2: Integration of cessation within routine training: Intense training of several days has been a feature of previous cessation interventions (6, 7). Such resource-intensive exercises conducted outside regular, routine programme training can be unfeasible when attempting to scale-up. Yet, strengthening capacity of the implementing organisation is a key Expandnet step (see Table 2) and low confidence of health workers to deliver cessation has been identified previously $(14,15)$. Our second strategy was to train a core of NTP trainers using the intervention materials with supporting videos (see Table 1 ) to roll-out cessation training to TB health workers as part of routine programme training.

Table 2

Characteristics of learning sites

\begin{tabular}{|lll|}
\hline Total facilities & Hospitals & Primary health care clinics \\
\hline Bangladesh (15) & 3 public & 12 public \\
\hline Nepal (18) & 3 NGO & 15 public \\
\hline Pakistan (59) & & \\
\hline District 1 Peshawar (28) & 9 private/NGO & 4 public \\
& 9 public & 6 private/NGO \\
\hline District 2: Kohat (10) & 2 public & 6 public \\
& & 2 private/NGO \\
\hline District 3 Abbottabad (9) & 5 public & 2 public \\
& & 2 private \\
District 4: Madan (12) & 6 public & 4 public \\
& 1 private/NGO & 1 private \\
\hline
\end{tabular}

Strategy 3) Including tobacco-use in recording, monitoring and supervision: To highlight the priority given to tobacco cessation and track implementation, TB managers recommended adding tobacco use to TB reporting forms and NTP indicators. We held discussions with the central TB programmes to revise national TB reporting forms and redesigned existing TB reporting forms for use in the learning sites to include space to record for each patient: a) smoking status at start of treatment, b) if cessation advice had been given and c) smoking status at end of treatment.

Strategy 4) embedding research within TB programmes: TB and Tobacco consortium researchers in all three countries drew on approaches to embed research for health policy and system change as recommended by Olivier et al (2017) (26) and specified within the WHO 2012 strategy on health policy and systems research (27), by: i) using 'insider-researchers', ii) working with NTPs in the design of the study and identification of learning sites, iii) immersion of researchers within the health system through participation in existing fora, planning events and regular meetings at national and sub-national levels and iv) identifying windows of opportunity for meaningful engagement.

Having agreed these strategies with the TB programmes, this study aimed to understand the extent and processes of vertical scale-up (institutionalisation) and horizontal scale-up (increased coverage).

\section{Context}

Within many high-burden countries, including in Bangladesh, Nepal and Pakistan, TB diagnosis and treatment has been integrated within all levels of care in the health system using the Directly Observed Treatment Short-course (DOTS) process (28) of six months of treatment for patients with drug-sensitive TB. In Pakistan TB care is integrated within the primary health care system which consists of a mix of public and private providers. Within the federal context, the programme is implemented by the district health authorities with the support of Provincial TB Control Programs and national leadership from the Common 
Unit for TB, AIDS and Malaria. In Bangladesh, the National TB Control Programme, under the Directorate General of Health Services, manages the programme centrally, delivering TB care through a mix of public, private and NGO providers.. Following constitutional reform in 2015, Nepal introduced a three-tier federal system, devolving management of TB services to local (municipality) level, with support from provincial Health Directorates and the National TB Control Centre at federal level. A mix of public, private and NGO providers deliver TB care integrated within the primary health care system.

\section{Methods}

We used an implementation science approach, allowing flexibility to enable close collaboration with policy makers and national TB programmes (29). Our study was based on a convergent mixed methods design, combining quantitative and qualitative findings at the analysis stage (30), to understand how well the strategies encouraged both the vertical (institutionalisation) and horizontal (increased coverage) scale-up of the tobacco cessation intervention.

\section{Leaming sites}

The selection of the learning sites was determined by NTPs based on local capabilities and interest to implement. In Pakistan, the national programme invited all provinces to participate. Khyber Pakhtunkhwa Province (KPP) volunteered to implement the intervention in 59 facilities out of the 121 in the province, selected to include urban, rural, public and private. In Nepal, one NGO-run community hospital, two NGO-run TB referral centre, 15 public primary care facilities within the Kathmandu district and Lalitpur district were selected. In Bangladesh, 15 facilities - 12 Upazilla health complexes and three district hospitals from three districts were selected to cover both rural and urban settings (see Table 2).

\section{Quantitative methods:}

As an indication of the likelihood of vertical scale-up within the TB programme, we assessed the impact of training on health worker confidence to deliver the intervention. Participants were asked to complete a pre-tested questionnaire (9) to assess capacity, opportunity and motivation for provision of cessation support before and after training. The pre- and post-training questionnaires were collected on paper and recorded in excel. We also recorded the number of trainers trained and any subsequent training provided to TB health workers in the learning sites or beyond.

To assess the implementation of the intervention within the facilities (vertical scale-up), we collected routine data from the revised NTP reporting forms for all drug-sensitive TB patients 15 years and above in the three countries. We collected data for a period of six months from January to June 2019. However, only three months' data (April- June 2019) were collected in Nepal and two districts in Bangladesh. To aid comparability the total number of patients and the monthly mean number of patients are presented (see Table 5). The routine data were captured during our research team's visits to the learning sites. These included the total number of drug-sensitive TB patients 15 years and above and whether their smoking status was recorded and whether they had received cessation advice. To assess correct usage of the new reporting columns, we estimated the proportion of appropriately completed data entry cells for the columns on tobacco-use and tobacco support for all adult TB patients.

Costs: We used an activity-based cost-analysis approach (31) to estimate the cost of implementation of the intervention per drug-sensitive TB patient (15 years and over) in learning sites. We collected data of: i) personnel salaries, fees, and time-taken in programme-related activities, including intervention delivery and training; ii) printing and disseminating programme/intervention materials; iii) number of intervention sessions delivered. Costs did not include venue utilities (water, electricity, etc.), administrative activities (preparation meetings, organisation contacts, etc.), logistics (stationery, refreshments, etc.) and salary on-costs (contribution to pension, health insurance, etc.) if applicable.

Qualitative methods: TB and Tobacco Consortium researchers, national to each country, with experience in qualitative methods and the health system contexts, observed training delivery and the implementation of the intervention in each facility. They interviewed health workers and managers to understand the facilitators and barriers to both vertical and horizontal scale-up. Training sessions were observed using a structured guide to record the length and content of the training, use of intervention materials and videos, use of interactive methods such as role-play and quality of training provided. These observations focused on patients' interaction, use of the materials and completion of the reporting forms. To determine the size of the interview sample, we drew on principles of 'information power' (32). Given our aim to understand varied perspectives we purposively sampled health workers, managers and policymakers for semi-structured qualitative interviews from public, private and NGO facilities within the learning sites and TB programme managers at municipality, district, provincial and national level (Nepal $n=13$; Pakistan $n=19$; Bangladesh: $n=12$; see Table 3). All interviews were audio-recorded and translated into English. The use of the Consolidated Framework for Implementation Research (CFIR) (33) within both the analysis and the interview guide further strengthened the 'information power' of the study. 
Table 3

Characteristics of qualitative participants

\begin{tabular}{|c|c|c|c|}
\hline ID & Sex & Type/Level of Organization & Designation \\
\hline \multicolumn{4}{|l|}{ Nepal } \\
\hline NP1 & M & National TB Programme & Technical officer \\
\hline NP2 & M & National TB Programme & Technical officer \\
\hline NP3 & $\mathrm{F}$ & Municipality office & Technical officer \\
\hline NP4 & M & Public TB facility & Facility manager \\
\hline NP5 & $\mathrm{F}$ & District Health office & TB health worker \\
\hline NP6 & $\mathrm{F}$ & NGO TB facility & Senior manager \\
\hline NP7 & $\mathrm{F}$ & Public TB facility & TB health worker \\
\hline NP8 & $\mathrm{F}$ & Public TB facility & TB health worker \\
\hline NP9 & $\mathrm{F}$ & Public TB facility & TB health worker \\
\hline NP10 & $\mathrm{F}$ & Public TB facility & TB health worker \\
\hline NP11 & $\mathrm{F}$ & Public TB facility & TB health worker \\
\hline NP12 & $\mathrm{F}$ & Public TB facility & TB health worker \\
\hline NP13 & $\mathrm{F}$ & NGO TB facility & TB health worker \\
\hline \multicolumn{4}{|c|}{ Pakistan } \\
\hline PK1 & M & Public TB facility & TB facility manager \\
\hline PK2 & M & Private TB facility & TB health worker \\
\hline PK3 & M & Private TB facility & TB health worker \\
\hline PK4 & M & Public TB facility & TB health worker \\
\hline PK5 & M & Private TB facility & TB health worker \\
\hline PK6 & M & Private TB facility & TB health worker \\
\hline PK7 & $\mathrm{F}$ & Public TB facility & TB health worker \\
\hline PK8 & M & District government & Technical officer \\
\hline PK9 & M & Private TB facility & TB health worker \\
\hline PK10 & M & District government & Senior manager \\
\hline PK11 & M & Public TB facility & TB health worker \\
\hline PK12 & M & Public TB facility & TB health worker \\
\hline PK13 & M & Public TB facility & TB health worker \\
\hline PK14 & M & Private TB facility & TB health worker \\
\hline PK15 & M & Private TB facility & TB health worker \\
\hline PK16 & M & Private TB facility & TB health worker \\
\hline PK17 & M & Provincial government & Senior manager \\
\hline PK18 & $M$ & Public TB facility & TB health worker \\
\hline PK19 & $M$ & Private TB facility & TB health worker \\
\hline \multicolumn{4}{|c|}{ Bangladesh } \\
\hline BD1 & M & Public TB facility & TB health worker \\
\hline BD2 & M & Public TB facility & TB health worker \\
\hline BD3 & $\mathrm{F}$ & Public TB facility & TB health worker \\
\hline BD4 & M & Public TB facility & TB health worker \\
\hline BD5 & $M$ & Public TB facility & TB health worker \\
\hline BD6 & $M$ & Public TB facility & TB health worker \\
\hline
\end{tabular}

Page $7 / 20$ 


\begin{tabular}{|llll|}
\hline ID & Sex & Type/Level of Organization & Designation \\
\hline BD7 & M & Public TB facility & TB health worker \\
\hline BD8 & F & National TB Programme & Senior manager \\
\hline BD9 & F & National TB Programme & Senior manager \\
\hline BD10 & M & District TB Programme & Senior manager \\
\hline BD11 & M & District TB Programme & Technical officer \\
BD12 & M & Public TB facility & Senior manager \\
\hline
\end{tabular}

\section{Analysis}

The questionnaire data were analysed using descriptive statistics and paired t-test in Stata version 16.1 to identify any significant changes in individual responses before and after the training. The routine facility data were analysed to identify proportions for each indicator. Given the different time periods of data collection, monthly mean patient numbers were calculated. The reported number of smokers identified were compared to the expected number of smokers given the age adjusted prevalence of current tobacco smoking estimates provided by WHO based on 2017 data (11) and $95 \%$ confidence intervals around these ratios were calculated.

Costs were collected in respective countries' currencies: Bangladeshi Taka (BDT), Nepalese rupee (NPR), Pakistani rupee (PKR) and converted to US dollars (May 9, 2019 price: USD1.0 = BDT84.5 = NPR112.1 = PKR142.0). As three months data were collected from some learning sites, for comparison, the number of patients and smokers identified over three months was doubled to match observations over six months. The total costs in the learning sites were calculated and divided by the total TB patients reported in the observation period to derive a per patient cost.

Framework approach (34) was used to structure the analysis against the CFIR constructs, with further codes added to align findings with our four strategies. Transcripts of the first two interviews conducted in each country were double-coded to enable reflection on the interview process and to refine the interview guide to further explore concepts of the CFIR. Consistency of use of the CFIR by the country research teams was enabled through a three-day analysis workshop.

The STARI guidelines have been followed in the reporting of this study (35).

\section{Findings}

Our findings are presented against each of the four systems-orientated scale-up strategies. The activities used to implement all four strategies are mapped against the ExpandNet 9 steps in Table 4. The table also provides a summary of the lessons learned, drawing on the qualitative findings and reflections of the research team. 
Table 4

Mapping TB\&Tobacco Consortium actions to ExpandNet Scale-up Steps and Framework

\section{ExpandNet nine TB \& Tobacco Consortium \\ steps to scale-up \\ Actions in relation to \\ Expandnet's 'CORRECT'1 \\ intervention attributes to \\ enable scale-up and \\ principles of enhanced \\ scalability, systems thinking, \\ sustainability, equity.}

Step 1: Planning actions to increase the scalability of the innovation

Adaptation of cessation intervention found effect Asia $(0, C)$. through research in South

Engagement with national, provincial, regional TB programmes to adapt intervention and throughout the project $(R)$.

Reduced intervention content for shorter $10 \mathrm{~min}$ cessation consultations (Co).

Adding one-page desk guide for easy reference (E.)

Policy and guideline review $(\mathrm{R})$.
Step 2: building the capacity of the user organisation for scale-up

Training trainers in the TB health system (Co).

Working with NTPs to identify NTP staff to train as trainers $(\mathrm{R})$.

Designing short training sessions for use in routine TB programme (Co) with videos to maintain quality and consistency (C).

Assessing capacity, opportunity and motivation of TB health professionals $(\mathrm{T})$.

Step 3: Assessing the environment and planning actions to increase the potential for scaling-up success

\section{Lessons learned and reflections of TB \& Tobacco Consortium Actions}

RCT evidence from Pakistan and Bangladesh (7) of the effectiveness of the 10min cessation consultation enhanced the credibility of the intervention for policy makers and practitioners, particularly as evidence showed the relative advantage over pharmaceutical interventions or no quit support $(6,48)$.

Facilitating TB health workers to adapt and apply the intervention to their context helped with relevance, ownership and compatibility.

Policy review highlighted limited attention to tobacco cessation in existing policies and plans, indicating that although there is no comprehensive tobacco cessation programme in Bangladesh, Pakistan or Nepal, concern that felt need/relevance may not be great.
Developing and filming videos provided an opportunity for further engagement of NTP staff and TB health workers at all levels increased buy-in of TB programmes e.g. Nepal's NTP director introduced the training video.

Filming in TB clinics and modelling real-life consultations enhanced relevance.

Challenging to identify trainers likely to subsequently train others e.g. Nepal, 8 trainers trained, but only 2 delivered training to TB health workers.
Identifying health system levers for vertical and horizontal scale-up (Co)

Engagement with NTPs at national (Bangladesh), national and provincial (Pakistan) and municipalities (Nepal) to identify learning sites $(\mathrm{R}, \mathrm{O}$ T)

Redesign of NTP recording and reporting forms $(\mathrm{Co}, \mathrm{T})$

Redesign of NTP supervision forms (Co)

Supporting and assessing the delivery of training of health workers and dissemination of materials (Co, $\mathrm{T})$
IR studies (14-16), workshops with TB managers, health workers, supervisors and research team's in-depth knowledge of TB programmes in all three countries vital to identify health system levers

Adapting existing reporting forms and guidelines and training programmes rather than developing parallel systems enhanced compatibility but was challenging to implement.

Despite increases in COM-B questionnaire scores following the short training, demand for longer training and regular refreshers highlighted that training is also seen as an incentive.

In general, NTP supervision in all three countries focused on checking reporting forms rather than support to provide quality care. Greater early engagement of first line supervisors (e.g. Programme Officers in Bangladesh) in future could help address this. 
ExpandNet nine steps to scale-up

\section{TB \& Tobacco Consortium Actions in relation to Expandnet's 'CORRECT'1 intervention attributes to enable scale-up and principles of enhanced scalability, systems thinking, sustainability, equity.}

Step 4: Increasing the capacity of the resource team to support scaling up

Step 5. Making strategic choices to support vertical scale-up (institutionalisation)

Step 6. Making strategic choices to support horizontal scale-up (increased coverage) amenable to change ( $\mathrm{Ra}$, briefs and workshops (O, Ra
In-country research teams build relationships with NTPs (R, Co).

Extended periods of research through multiple studies with national TB programmes $(\mathrm{O}, \mathrm{R}, \mathrm{Co})$.

Co-I and TB focal point as 'insider-researchers' in Pakistan (C, R, Co).

Focusing on health system levers most Co).

Identification of a mix of rural, urban, public, private, large and small learning sites $((\mathrm{O}, \mathrm{R}, \mathrm{Co})$.

Workshops and presentations at key events (C, Co)

Sharing findings, including costs, from learning sites via policy T)

Way Forward workshops with NTP, donor and NGO stakeholders in all three countries to build on findings to plan scale-up beyond learning sits $(C, O, R)$

Feeding into TB strategic planning processes (R)

Engaging global policy makers (WHO, UNDP, Tobacco Control) and International Union against TB and Lung Disease $(C, R)$.
Lessons learned and reflections of TB \& Tobacco Consortium Actions

Senior members of the research team have long standing relationships with NTP at policy and programme level and mutual respect developed through engagement in multiple studies.

More junior researchers had to build working relationships, this was particularly challenging for early-career female researchers in male-dominated hierarchies.

Building these relationships was further challenged by the frequent transfer of senior NTP officials, e.g. six different NTP Line Directors in Bangladesh over the study period.

Challenging for researchers to stay within their research role and not influence implementation.

Insights of 'insider researchers' was valuable in ensuring compatibility and relevance of scaleup strategies.

In Bangladesh and Nepal, learning sites were agreed with NTP at national (Bangladesh) and municipal level (Nepal), but more limited ownership of implementation by NTPs.

Detailed knowledge of NTPs by the research team was key in identifying the most strategic events to engage and seizing opportunities to engage and influence in e.g. Chest Society conference and Interprovincial and inter-district meetings in Pakistan; NTP Technical Working Group and WHO events in Nepal; Coordination workshops/meetings with National Tobacco Control Cell, and Non-Communicable Disease Control Programme, Ministry of Health and Family Welfare in Bangladesh.

Rapid recognition of the need to engage at municipal level within the new federal context of Nepal to identify learning sites and train as trainers supported ownership and integration of the intervention at municipal level.

Inclusion of private sector and NGO providers to enhance testability $(T)$ within different contexts vital within the pluralistic health system.

Collection of cost data valued by decision-makers within NTPS

Multiple channels are needed for dissemination e.g. 'Way Forward' workshops, policy briefs and availability of all materials in Urdu, Bengali and Nepali

Dissemination most effective when linked to forward planning.

Integration of tobacco cessation within TB programmes gaining global traction, but TB and Tobacco advisors working in silos. Growing recognition of the need for tobacco indicators within Global Fund proposals and monitoring.

Engagement of senior researchers in the team in health sector planning (e.g. in Bangladesh: Annual Programme Review (APR) and Mid Term Review (MTR) of the 4th health sector programme of Bangladesh, road map to make Bangladesh tobacco free by 2040). In Pakistan engagement in processes to develop 2020-23 strategic plan, which highlighted the success in learning sites and emphasised tobacco cessation. In Nepal, engagement in the development of NTP's National Strategic Plan and funding proposal to GFATM helped to advocate and incorporate research findings to support horizontal scale up.

In Nepal, embedding research within a government in transition to federalisation was challenging, but building alliances within and beyond NTP provided opportunities for horizontal scale-up.

Tension between keeping focused on delivery of the existing intervention and requests from learning sites to extend the work e.g. to include community education campaigns on tobacco, to use within MDR TB programmes, greater emphasis on smokeless tobacco.

Adaptation (e.g. group sessions in Pakistan's busy clinics) and personalisation of the delivery of the intervention helped ownership and adoption of the intervention.
Step 7. Determining the role of diversification
Emphasising core elements of the interventions within the health worker guide which accompanies the Co)

Encouraging adaptation to context (Co). 


\begin{tabular}{|c|c|c|}
\hline $\begin{array}{l}\text { ExpandNet nine } \\
\text { steps to scale-up }\end{array}$ & $\begin{array}{l}\text { TB \& Tobacco Consortium } \\
\text { Actions in relation to } \\
\text { Expandnet's 'CORRECT'1 } \\
\text { intervention attributes to } \\
\text { enable scale-up and } \\
\text { principles of enhanced } \\
\text { scalability, systems thinking, } \\
\text { sustainability, equity. }\end{array}$ & Lessons learned and reflections of TB \& Tobacco Consortium Actions \\
\hline $\begin{array}{l}\text { Step 8. Plan actions } \\
\text { to address } \\
\text { spontaneous scale- } \\
\text { up }\end{array}$ & $\begin{array}{l}\text { Videos and materials } \\
\text { freely-available on-line to } \\
\text { encourage spontaneous } \\
\text { scale-up (E, Co) } \\
\text { in Link to on-line materials } \\
\text { in all printed intervention } \\
\text { materials (E, Co) } \\
\text { All materials in multiple } \\
\text { languages (Urdu, Bengali, } \\
\text { Nepali and English) }(E, C o)\end{array}$ & $\begin{array}{l}\text { Organisations may take the initiative but only implement part of the intervention, e.g. NCDC } \\
\text { programme of Bangladesh endorsed the leaflet and printed and distributed nationally (from their } \\
\text { own budget) } \\
\text { Materials adapted for use in large private TB providers in Pakistan. } \\
\text { In Nepal, some intervention materials (i.e posters and leaflets) were considered as NTP } \\
\text { resources and so supplied to health facilities through NTP. }\end{array}$ \\
\hline $\begin{array}{l}\text { Step 9. Finalising } \\
\text { scaling-up strategy } \\
\text { and identifying next } \\
\text { steps }\end{array}$ & $\begin{array}{l}\text { Way-forward workshops } \\
\text { with national TB } \\
\text { programme policy-makers } \\
\text { designed to identify next } \\
\text { steps }(C, R, C o)\end{array}$ & $\begin{array}{l}\text { Challenges of agreeing next steps within federal context of Pakistan, and within context of } \\
\text { structural reorganisations in newly federal Nepal } \\
\text { coordination with NGOs (e.g. BRAC) and development partners (e.g. Global Fund) in Bangladesh } \\
\text { - More work at global level needed to shape indicators (e.g. Global Fund). }\end{array}$ \\
\hline
\end{tabular}

\section{Strategy 1: Simple and adaptable intervention}

The facility and qualitative data shed light on the extent and nature of implementation of the intervention with TB patients. Table 5 shows the numbers of smokers identified compared to the expected number of smokers according to standardised WHO estimates and the proportion advised to quit. 
Table 5

Smokers identified and advised on cessation among all TB patients from routine records

\begin{tabular}{|c|c|c|c|c|c|c|c|c|c|c|}
\hline \multirow{2}{*}{$\begin{array}{l}\text { Country: } \\
\text { WHO } \\
\text { smoking } \\
\text { prevalence } \\
\text { (2017): }\end{array}$} & \multicolumn{4}{|c|}{$\begin{array}{l}\text { Bangladesh } \\
\text { Male: 41.4\%; Female:1.4\%; All:21.3\% }\end{array}$} & $\begin{array}{l}\text { Nepal } \\
\text { M:33.7\%; }\end{array}$ & \multicolumn{5}{|c|}{$\begin{array}{l}\text { Pakistan, Khyber Pakhtunkhwa (KP) Province } \\
\text { Male:31\%; Female: } 2.8 \% \text {; All: } 16.9 \%\end{array}$} \\
\hline & & & & & All: $21.3 \%$ & & & & & \\
\hline $\begin{array}{l}\text { Learning } \\
\text { sites: }\end{array}$ & Narayanganj & Gazipur & Dhaka & $\begin{array}{l}\text { Bangladesh } \\
\text { Total }\end{array}$ & $\begin{array}{l}\text { Kathmandu/ } \\
\text { Lalitpur }\end{array}$ & Abbottabad & Kohat & Mardan & Peshawar & $\begin{array}{l}\text { KP Province } \\
\text { Total }\end{array}$ \\
\hline $\begin{array}{l}\text { Number of } \\
\text { facilities }\end{array}$ & 5 & 5 & 5 & 15 & 18 & 9 & 10 & 12 & 28 & 59 \\
\hline $\begin{array}{l}\text { Data } \\
\text { collection } \\
\text { period }\end{array}$ & 6 months: & 3 months & & & 3 months & 6 months & & & & \\
\hline $\begin{array}{l}\text { Total } \\
\text { patient } \\
\text { numbers } \\
\text { from } \\
\text { routine } \\
\text { data over } \\
\text { study } \\
\text { period } \\
\text { (M:male } \\
\text { and } \\
\text { F:female) }\end{array}$ & $\begin{array}{l}2808 \\
(\mathrm{M}: 1551 ; \\
\mathrm{F}: 1257)\end{array}$ & $\begin{array}{l}1329 \\
\text { (M: 800; } \\
\text { F: } 529)\end{array}$ & $\begin{array}{l}1234 \\
(\mathrm{M}: 711 ; \\
\mathrm{F}: 523)\end{array}$ & $\begin{array}{l}5371 \\
(M: 3062 ; \\
F: 2309)\end{array}$ & $\begin{array}{l}288 \\
(M: 148 \\
F: 140)\end{array}$ & $\begin{array}{l}851 \\
\text { (M:428; } \\
\text { F:423) }\end{array}$ & $\begin{array}{l}580 \\
\text { (M:283; } \\
\text { F:297) }\end{array}$ & $\begin{array}{l}1081 \\
\text { (M:554; } \\
\text { F:527) }\end{array}$ & $\begin{array}{l}2577 \\
(\mathrm{M}: 1302 ; \\
\mathrm{F}: 1275)\end{array}$ & $\begin{array}{l}5089 \\
(M: 2567 \\
F: 2522)\end{array}$ \\
\hline $\begin{array}{l}\text { Male TB } \\
\text { patients } \\
\text { monthly } \\
\text { mean }\end{array}$ & 259 & 267 & 237 & 763 & 49 & 71 & 47 & 92 & 217 & 427 \\
\hline $\begin{array}{l}\text { Female TB } \\
\text { patients } \\
\text { monthly } \\
\text { mean }\end{array}$ & 210 & 176 & 174 & 560 & 47 & 71 & 50 & 88 & 213 & 422 \\
\hline $\begin{array}{l}\text { Total TB } \\
\text { patients } \\
\text { monthly } \\
\text { mean }\end{array}$ & 468 & 443 & 411 & 1322 & 96 & 142 & 97 & 180 & 430 & 849 \\
\hline $\begin{array}{l}\text { Patients } \\
\text { asked } \\
\text { about } \\
\text { tobacco } \\
\text { use } \\
\text { monthly } \\
\text { mean }\end{array}$ & $\begin{array}{l}468 \\
(100 \%)\end{array}$ & $\begin{array}{l}443 \\
(100 \%)\end{array}$ & $\begin{array}{l}411 \\
(100 \%)\end{array}$ & $\begin{array}{l}1322 \\
(100 \%)\end{array}$ & $\begin{array}{l}96 / 96 \\
(100 \%)\end{array}$ & $\begin{array}{l}142 / 142 \\
(100 \%)\end{array}$ & $\begin{array}{l}97 / 97 \\
(100 \%)\end{array}$ & $\begin{array}{l}180 / 180 \\
(100 \%)\end{array}$ & $\begin{array}{l}430 / 430 \\
(100 \%)\end{array}$ & $\begin{array}{l}849 / 849 \\
(100 \%)\end{array}$ \\
\hline $\begin{array}{l}\text { Male } \\
\text { smokers } \\
\text { identified } \\
\text { among all } \\
\text { TB } \\
\text { patients, } \\
\text { monthly } \\
\text { mean }\end{array}$ & $\begin{array}{l}130 / 259 \\
(50.1 \%)\end{array}$ & $\begin{array}{l}110 / 267 \\
(41.1 \%)\end{array}$ & $\begin{array}{l}75 / 237 \\
(31.6 \%)\end{array}$ & $\begin{array}{l}321 / 763 \\
(42.1 \%)\end{array}$ & $\begin{array}{l}11 / 49 \\
(22.4 \%)\end{array}$ & $\begin{array}{l}21 / 71 \\
(29.6 \%)\end{array}$ & $\begin{array}{l}6 / 47 \\
(13.1 \%)\end{array}$ & $\begin{array}{l}8 / 92 \\
(8.9 \%)\end{array}$ & $\begin{array}{l}27 / 217 \\
(12.4 \%)\end{array}$ & $\begin{array}{l}62 / 427 \\
(14.5 \%)\end{array}$ \\
\hline $\begin{array}{l}\text { Expected } \\
\text { male } \\
\text { smokers } \\
\text { based on } \\
\text { WHO } 2017\end{array}$ & & & & $\begin{array}{l}316 / 763 \\
(41.4 \%)\end{array}$ & $\begin{array}{l}16.5 / 49 \\
(33.7 \%)\end{array}$ & & & & & $\begin{array}{l}132.37 / 427 \\
(31 \%)\end{array}$ \\
\hline $\begin{array}{l}\text { Female } \\
\text { smokers } \\
\text { identified } \\
\text { among all } \\
\text { TB } \\
\text { patients, } \\
\text { monthly } \\
\text { mean }\end{array}$ & $\begin{array}{l}0.33 / 210 \\
(0.2 \%)\end{array}$ & $\begin{array}{l}0 / 176 \\
(0 \%)\end{array}$ & $\begin{array}{l}0 / 174 \\
(0 \%)\end{array}$ & $\begin{array}{l}0.33 / 560 \\
(0.06 \%)\end{array}$ & $\begin{array}{l}4 / 47 \\
(8.5 \%)\end{array}$ & $\begin{array}{l}0.5 / 71 \\
(0.7 \%)\end{array}$ & $\begin{array}{l}0 / 50 \\
(0 \%)\end{array}$ & $\begin{array}{l}0 / 88 \\
(0 \%)\end{array}$ & $\begin{array}{l}0 / 88 \\
(0 \%)\end{array}$ & $\begin{array}{l}0.5 / 422 \\
(0.1 \%)\end{array}$ \\
\hline $\begin{array}{l}\text { Expected } \\
\text { female } \\
\text { smokers } \\
\text { based on } \\
\text { WHO } 2017\end{array}$ & & & & $\begin{array}{l}8 / 560 \\
(14.3 \%)\end{array}$ & $\begin{array}{l}4.14 / 47 \\
(0.088)\end{array}$ & & & & & $\begin{array}{l}11.816 / 422 \\
(2.8 \%)\end{array}$ \\
\hline
\end{tabular}




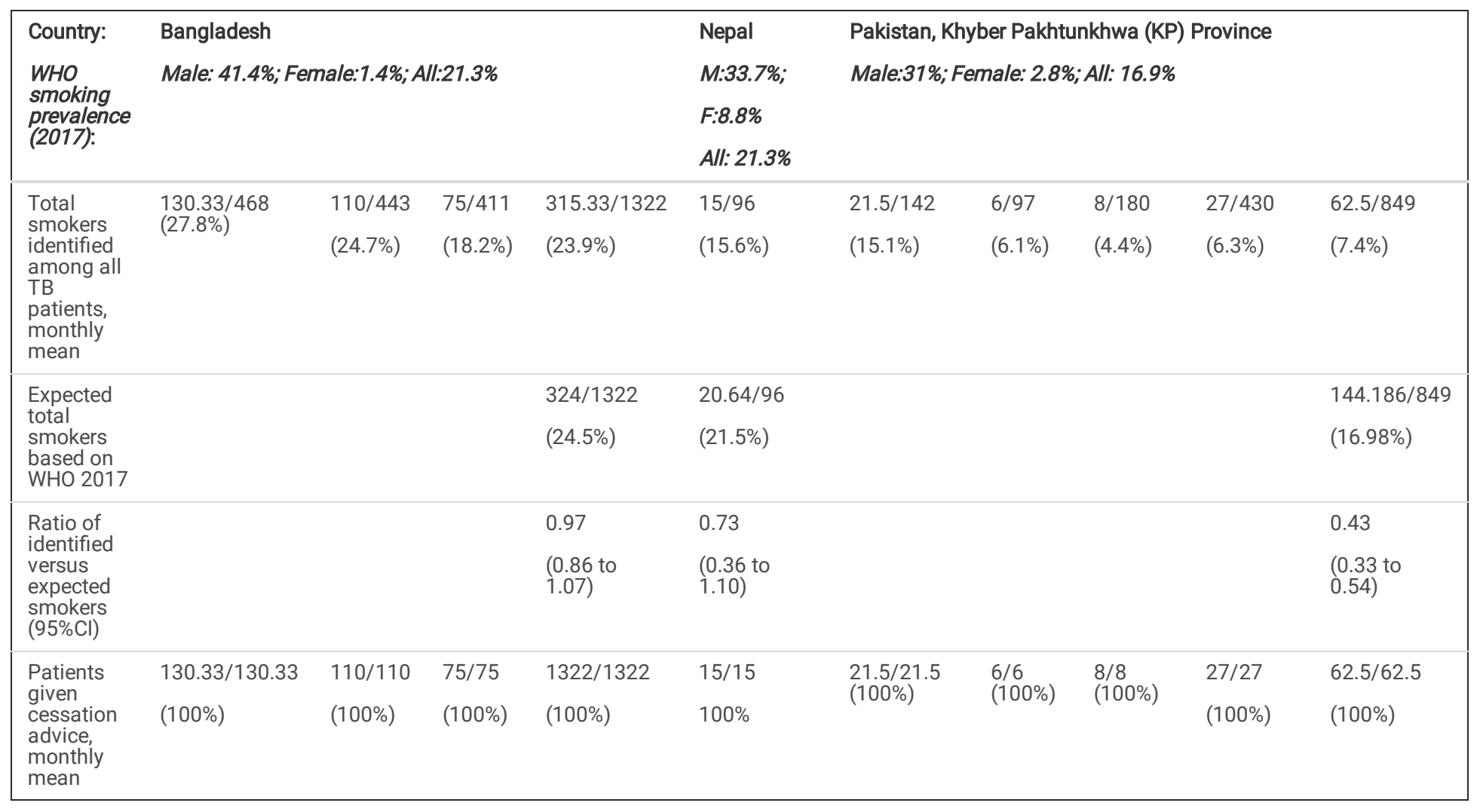

In Bangladesh and Nepal the health workers identified less smokers than would be expected based on WHO (2017) however these were not statistically significant. In Pakistan the ratio of identified versus observed shows statistically significantly few smokers identified (ratio: $0.4395 \% \mathrm{Cl} 0.33$ to 0.54 ) than would be expected given WHO estimates of prevalence. The qualitative findings point to a combination of patient, health worker and site factors. Several health workers mentioned the need to build rapport with their patients before asking about tobacco use, often over a number of visits by the patient to collect their TB medicines. This was despite indicating a high level of confidence in asking about tobacco use in the post training questions, with all participants scoring at least 4 out of a potential 5, for totally confident, on the questionnaire Likert scale. This did differ depending on the gender of the provider, with male providers feeling more confident to ask male patients, and female health workers to ask female patients.

Once patients had been identified, the routine reporting forms in all countries indicated that all patients had been given support to quit. The qualitative findings noted use of the flipbook and desk guide. However, the data also shed light on how minimal the advice given often was. Many health workers reported challenges in delivering the behaviour support as per the intervention design with health workers in busy clinics and urban settings rarely able to spend the time required to go through every page of the flipbook:

"I've only ever used the flipchart for one patient. My patients cannot spend much time as all of them are workers. They take a short break from work to come, so I cannot explain to them in detail" (NP8 Female TB health worker, public facility, Nepal).

Many health workers felt they had been able to internalise the key messages and could deliver these without using the flipbook, filling in any gaps in subsequent patient consultations. In the busiest learning sites in Pakistan, health workers had adapted the intervention by delivering it to groups of patients.

Where our learning sites included both public and private facilities, the qualitative findings identified similar constraints across both settings, although private providers also mentioned the challenges of balancing implementation of the intervention with the specific requirements of their own organisations:

"It can be difficult because we have our own rules here and we cannot go above a certain limit [of interventions delivered]." (PK19: Male TB health worker, private facility, Pakistan).

\section{Strategy 2: Integration of cessation within routine training:}

The national TB programmes identified staff at national and sub-national levels to be trained as trainers in each country. The training of trainers (ToT) workshops took between 3 and 6 hours. During these ToT sessions, participants identified future events, such as district quarterly and monthly meetings to deliver the 1 to 2 hour training session with TB health workers. As shown in Table 6, the numbers of trainers trained varied between contexts, depending on the level of engagement of NTPs. The extent to which these trainers then trained TB health workers also varied. In Nepal, while eight NTP and municipal public health officers were trained as trainers, only two provided training to health workers in the subsequent training sessions. In both Bangladesh and Pakistan, trainers expanded their training sessions beyond the initial learning sites to train a further 32 TB health workers in Bangladesh and health workers in all 121 facilities in KP Province by the end of 2020. 
Table 6

Training of trainers and TB health workers change in capability for cessation

\begin{tabular}{|c|c|c|c|c|c|}
\hline & \multirow{3}{*}{$\begin{array}{l}\text { NTP staff } \\
\text { trained as } \\
\text { trainers }\end{array}$} & \multirow[t]{3}{*}{ TB health workers trained } & \multicolumn{3}{|c|}{ Capability Questionnaire } \\
\hline & & & $\begin{array}{l}\text { Before } \\
\text { training }\end{array}$ & $\begin{array}{l}\text { After } \\
\text { training }\end{array}$ & $\begin{array}{l}\% \text { Change }(95 \% \\
\text { Confidence }\end{array}$ \\
\hline & & & $\begin{array}{l}\text { Mean } \\
\text { (minimum, } \\
\text { maximum) }\end{array}$ & $\begin{array}{l}\text { Mean } \\
\text { (minimum, } \\
\text { maximum) }\end{array}$ & \\
\hline \multirow[t]{3}{*}{ Bangladesh } & \multirow[t]{3}{*}{4} & 37 & $97 \%$ & $99 \%$ & $3 \%$ \\
\hline & & 5 in learning sites & \multirow{2}{*}{$\begin{array}{l}(\min : 93 \% \\
\max : \\
100 \%)\end{array}$} & \multirow{2}{*}{$\begin{array}{l}(\min : 99 \% \\
\max : \\
100 \%)\end{array}$} & \multirow{2}{*}{$\begin{array}{l}(95 \% \mathrm{Cl}:-0.6- \\
6 \%)\end{array}$} \\
\hline & & $\begin{array}{l}\text { Follow on training provided by research team and NTP trainers to } 32 \\
\text { health workers in addition to training sites }\end{array}$ & & & \\
\hline \multirow[t]{2}{*}{ Pakistan } & \multirow[t]{2}{*}{16} & \multirow{2}{*}{$\begin{array}{l}115 \text { Health workers trained in } 4 \text { districts } 115: 55 \text { Doctors, } 56 \text { DOTS } \\
\text { facilitators, } 4 \text { district data assistants Follow on training: all TB staff in } 121 \\
\text { facilities trained by } 2020\end{array}$} & $70 \%$ & $86 \%$ & $16 \%$ \\
\hline & & & $\begin{array}{l}(\min : 31 \% \\
\max : 99 \%)\end{array}$ & $\begin{array}{l}(\min : 21 \% \\
\max : 100 \%)\end{array}$ & $\begin{array}{l}(95 \% \mathrm{Cl}: 13- \\
19 \%)\end{array}$ \\
\hline \multirow[t]{2}{*}{ Nepal } & \multirow[t]{2}{*}{8} & 17: 11 TB health workers and 6 public health officers. & $59 \%$ & $81 \%$ & $22 \%$ \\
\hline & & No follow-on training beyond learning sites. & $\begin{array}{l}(\min : 36 \% ; \\
\max : 86 \%)\end{array}$ & $\begin{array}{l}(\min : 40 \% \\
\max : 94 \%)\end{array}$ & $\begin{array}{l}(95 \% \mathrm{Cl}: 16- \\
28 \%)\end{array}$ \\
\hline \multirow{3}{*}{$\begin{array}{l}\text { Combined } \\
\text { for all } 3 \\
\text { countries }\end{array}$} & \multirow[t]{3}{*}{28} & 169 trained initially & $69 \%$ & $86 \%$ & $17 \%$ \\
\hline & & 153 received follow-on training & (min: 31\%; & (min: $21 \%$ & \multirow{2}{*}{$\begin{array}{l}(95 \% \mathrm{Cl}: 14- \\
20 \%\end{array}$} \\
\hline & & & $\max : 100 \%)$ & $\max : 100 \%$ & \\
\hline
\end{tabular}

Qualitative observations of the training sessions highlighted the value of the videos in helping to maintain consistency in messages delivered and provide relevant demonstrations of rapport building and clear communication. Participants were observed to be more engaged and motivated in sessions where the trainers were able to use interactive methods and relate material to the realities of routine TB services.

Mixing different levels of seniority was practically necessary in several training sessions, however this undermined participation:

"It should have been a bit more interactive because I did not see any one from lower levels of staff participating. It was mostly one sided, doctors did participate a bit, but it was not adequate" (PK10: Male, senior district manager, Pakistan).

The need to keep the training short, did present challenges in ensuring interactive delivery, but this was seen by senior managers as vital for scale-up of the intervention:

"it would not be possible to include a half-day session within the current training programme. Rather a one-hour interactive session can be introduced" (BD8 Female, senior national TB manager, Bangladesh).

Despite the short duration of training and the challenges in quality, participants' questionnaire scores before and after the training showed an increase in their confidence to deliver cessation (see Table 6). Qualitative interviews highlighted areas of new knowledge for many participants, including increased understanding of the health dangers of smokeless tobacco.

Despite increasing their knowledge and confidence to provide cessation support, health workers in all three countries emphasised their preference for longer sessions and regular refresher training. While this was in part due to the high turnover of staff, training was also perceived as a form of incentive.

\section{Strategy 3) Including tobacco-use in recording, monitoring and supervision:}

Following a brief explanation of how to fill the revised recording forms during the training, the TB health workers were asked to use the revised forms version with the three new tobacco columns for a period of six months (January to June 2019). In Pakistan the provincial office mandated health workers to complete the revised forms instead of the existing NTP forms (Forms TB01, 02 and 03). In Bangladesh and Nepal, TB health workers had to complete both the standard TB programme form and the revised form. In Nepal and Bangladesh this process took some time to negotiate and establish, and ultimately the revised forms could only be trialled for three months.

The qualitative findings indicate that TB health workers did not find the additional three columns a burden to fill, and some mentioned that it acted as a reminder to raise tobacco use as an issue with their patients:

" There have been changes in the new register. So, when we need to fill up the form for registration, we need to ask about their smoking status. Even if we forget, since it is there in the register, we have to ask the patients" (NP7: Female TB health worker, public facility, Nepal).

Beyond monitoring tobacco cessation within the TB programme, and reminding health workers to ask about tobacco use, the reporting forms provided the basis for supervision within the facility and from district and provincial level.

"Being an in-charge [facility manager] it is my duty that I go and check if they are actually doing it. I check their data or I observe how they do the counselling of a patient who is a smoker and ask them to do it in front of me and wherever I see a deficiency I should rectify it" (PK1: Male TB manager, public facility,

Page 14/20 
Pakistan).

In Pakistan, the Provincial TB Programme adapted their supervision check-list to note any training on tobacco cessation and to assess the completeness of recording for tobacco status and cessation advice given. However, the qualitative findings highlighted how supervision visits from the district office to the facility level were often infrequent, and focused on checking data in the registers. The influence of supervision was particularly noted, with several facility managers, including those in the private sector revealing that they only changed to the new reporting forms and began using the intervention materials following a visit by the provincial TB focal person.

During the implementation of this study, the transition to a federal system was underway in Nepal and the changes in personnel, systems and roles of different government bodies, particularly between ministry and municipal levels, undermined attempts to include tobacco cessation within supervision and monitoring mechanisms:

"All the staff are in confusion on where we will be and what will we do. We are functioning under both the Health office and the municipality, with instructions coming from both bodies. We are in a dilemma on what we should do because of this..." (NP4: Male TB manager, public facility, Nepal).

Qualitative interviews and observations highlighted the challenges of influencing supervision practices within the context of the public private partnerships in all three countries. In Bangladesh, where TB services are delivered by multiple providers, including the government, NGOs and private providers, challenges were identified in developing and implementing supervision guidelines that would be used by all.

\section{Strategy 4) embedding research within the TB programmes:}

The extent to which we were able to embed the research within TB programmes differed across the countries. A key component of this strategy was the use of 'insider researchers'. In Pakistan, a senior member of the national-level Common Unit for TB (co-author RF) was also a co-investigator in the TB and Tobacco consortium and a senior manager within the KP provincial TB programme (co-author MD) was involved in data collection and analysis for the study. In Bangladesh and Nepal, the TB and Tobacco consortium researchers relied upon their existing relationships at national and district level. The frequent turn-over of key staff in both Bangladesh and Nepal further undermined progress towards ownership of the implementation and scale-up process.

The qualitative interviews highlight how in Bangladesh and Nepal, while staff were positive about the intervention, it was clearly seen as an initiative emanating from the research organisations, rather an initiative of the national TB programmes. In contrast, in Pakistan, the provincial TB programme (KP) felt strong ownership as evidenced by the regular supervision, subsequent role of out training and revised reporting forms to all 121 TB facilities in the province. Gaining national level support for the intervention and revision of policies, guidelines and reporting forms was more challenging, particularly in the context of Pakistan's federal system whereby each provincial TB programme must agree to any changes. Having a senior member of the national level CU as a co-investigator of the project was invaluable in influencing other provincial TB programmes. By the end of 2019, while not all TB forms have been revised to include the tobacco columns, the TB01, the form held by the patients and brought to each consultation has now been revised to include tobacco status and these revised forms will be rolled out nationally.

In Nepal, the timing of our study coincided with organisational changes due to federalisation making it challenging to embed the research within the NTP. Despite the continual engagement of the research team, policy support and resources for tobacco cessation were minimal within the TB sector plan (36).

"[To-date] the government has not allocated [any financial resources] nor has the international partner, Global Fund, allocated any amount for the TB \& Tobacco program" (NP2: Male technical officer, national TB centre, Nepal).

Given the challenges of embedding research when government organisations are undergoing extensive structural change, the team in Nepal used tactics of leveraging support of others e.g. WHO and sub-recipients of Global Fund (GFATM) and seizing opportunities to engage with NTP technical working groups. These efforts were realised when the independent team evaluating NTP recommended greater integration of tobacco cessation within the TB programme, resulting in the inclusion of indicators on tobacco-use and advice within national reporting forms and training for cessation support added to NTP routine training.

In Bangladesh, the team engaged closely with key government stakeholders in the Tobacco Control Cell and the Noncommunicable Diseases Control (NCDC) department as well as the National TB Programme to stimulate engagement with the project. Engaging with, and facilitating communication between, these national government departments was an important strategy for progressing scale-up and helped overcome challenges of relying on the support of one or two champions, particularly given the frequent change of TB programme officials, including NTP directors. There are some indications that these approaches acted as a catalyst for scale-up as the NCDC department used their own resources to print the intervention leaflet and disseminate it nationally. However, the pluralism of providers and the multiple donor-funded vertical programmes within Bangladesh's health sector were a further barrier to progressing scale-up:

"What is needed is coordinated efforts from everyone. The major obstacle is non-coordination of the operational plans and among DPs [development partners]. We have so many vertical programmes without any coordination. Leadership is another problem. Change in staff within different units every six months to a year slows down the progress of the work" (BD8: Female, senior manager, national TB programme, Bangladesh).

Embedding the research within the three countries required significant flexibility and opportunism to tailor tactics to the complex health systems with multiple providers and donors, frequently changing personnel and organisational structures.

\section{Estimated Costs}

The estimated costs over the six-month implementation within the learning sites in each country, including costs per patient are shown in Table 7. 
Table 7

Estimated costs (USD) of implementation in the learning sites over 6 months by country

\begin{tabular}{|llllllll|}
\hline Country & $\begin{array}{l}\text { Number of } \\
\text { facilities }\end{array}$ & $\begin{array}{l}\text { Total TB } \\
\text { patients }\end{array}$ & $\begin{array}{l}\text { Smokers } \\
\text { identified }\end{array}$ & & $\begin{array}{l}\text { Total personnel } \\
\text { cost Training }\end{array}$ & $\begin{array}{l}\text { Total personnel cost for } \\
\text { intervention delivery }\end{array}$ & $\begin{array}{l}\text { Total Cost } \\
\text { Intervention } \\
\text { Materials }\end{array}$ \\
\cline { 3 - 4 } & & & & $\begin{array}{l}\text { Cost per TB } \\
\text { patient }\end{array}$ \\
Bangladesh & 15 & 7934 & 1885 & $\$ 1196$ & $\$ 1047$ & $\$ 1473$ \\
\hline Nepal & 18 & 576 & 90 & $\$ 375$ & $\$ 92$ & $\$ 143$ \\
\hline Pakistan & 59 & 5089 & 375 & $\$ 3041$ & $\$ 687$ & $\$ 3746$ \\
\hline
\end{tabular}

Per-patient programme costs were 0.5 USD in Bangladesh, 2.8 USD in Nepal and 1.5 USD in Pakistan. While the costs of intervention delivery would increase with the number of patients treated, the training costs include the costs of training the trainers which can be considered as a one-off cost, hence the average costs per patient could potentially be reduced over time. These costs were shared with TB programme decision-makers in policy-briefs and as part of a series of workshops to facilitate further planning for scale-up.

\section{Discussion}

The four strategies were key in supporting vertical (institutionalisation) and to a lesser extent, horizontal scale-up (increased coverage) of the tobacco cessation intervention (see Fig. 1). In summary, the strategies had the following impact: i) reporting forms indicated all identified tobacco users were advised to quit. TB health workers did not identify all tobacco users, qualitative data showed health workers used the materials although not always as intended. Materials were disseminated by NTPs beyond the learning sites in all three countries indicating some level of horizontal scale-up; ii) training built the confidence and knowledge of TB health workers to deliver cessation support to patients and, as an indication of horizontal scale-up, was delivered beyond the learning sites in Bangladesh and Pakistan iii) the addition of reporting items on tobacco use and cessation advice to routine reporting forms was feasible for TB health workers to use in every-day practice and informed revisions to national reporting forms in Pakistan. The per-patient programme costs were low in all three countries, with the highest cost 2.8 USD in Nepal primarily due to low patient numbers. Costs would reduce with horizontal scale-up and a stepwise expansion could be considered to spread costs over a few years if needed.

There was much evidence of use of the intervention materials and of adaptation to fit social and cultural norms and to implement within busy TB clinics. Given the challenges of relying on self-report routine data, we cannot draw conclusions on the impact of the reduced and adapted intervention on cessation at six months. While the simplification of the intervention is necessary to facilitate both vertical and horizontal scale-up and has been identified as a predictor of successful scale-up $(21,37,38)$, the challenge for those developing interventions and planning their implementation is to determine how far the intervention can be reduced and adapted without undermining effectiveness. It has been argued that there may not necessarily be a 'voltage drop' in the effectiveness of interventions from efficacy trial to scale-up (39). Further, a less efficacious intervention with more reach may have a greater impact then a highly efficacious intervention with less reach. Research assessing the effect of the adaptation of interventions during scale-up is limited (40) and such studies would be a valuable contribution to the evidence base on sustainability. Approaches such as the Dynamic Sustainability Framework emphasise that sustainable scale-up requires continual learning and adaptation to improve the fit of interventions to local settings and contexts, and this enables ongoing improvement as opposed to diminishing outcomes over time (39). Increasing this level of fit is also a key element in the diffusion of innovations (41).

We found that changes to reporting forms encouraged implementation, provided programme level data on implementation and acted as a basis for, albeit limited, supervision. The term 'check-list' effect (42) has been coined to explain how the process of recording data triggers intervention implementation. Other studies highlight how changes to reporting forms need to be considered early in the intervention design process, or else can undermine attempts at implementation as found in the assessment of institutionalisation of evidence-based new born health interventions in Bangladesh (22). In high-income contexts, measurement of outcomes over time have been identified as supporting sustainability of the practice $(39,43)$.

Influencing progress towards horizontal scale-up of coverage beyond the learning sites was particularly challenging, as has been found for many other public health interventions $(20,21)$. Our fourth strategy of embedded research, while valuable for vertical scale-up, proved particularly important as a catalyst to horizontal scale-up or increased coverage. The inclusion of 'insider-researchers' (26) in Pakistan may well have stimulated this level of commitment. This has been identified as a key strategy for embedded health policy and systems research $(26,27)$. The importance of champions and strong leadership is a consistent theme within scale-up models and frameworks $(21,38,44)$ as well as being identified in step 2 of the ExpanNet process $(20)$. However, the experiences from Bangladesh and Nepal highlight that relying on champions alone is not sufficient, particularly where health systems are undergoing major organisational change, as in Nepal and have frequent senior staff turn-over and multiple providers, as in Bangladesh. Deploying multiple strategies, including building alliances with other health system actors and engaging in appropriate fora helped scale-up in these contexts. Pursuing these strategies in Nepal and Bangladesh was possible due to the close partnership between the research teams, NTPs and the wider health system. These long-standing connections provided the researchers with the 'deep knowledge' required to build effective networks and take advantage of opportunities to influence scale-up (45).

Our approach of focusing on four clear strategies concurs with Milat's (2015) review which identified a well-defined scale-up strategy as key (21). Finding the most appropriate mix of strategies for the context is fundamental to steps 5 and 6 in the Expandnet framework. While ExpandNet present the process of scale-up as a series of linear steps, our experience emphasises the need for a flexible, iterative approach. While it is advantageous to identify clear strategies at the start of the process, flexibility to change course is also needed to respond to the complexity of health systems in dynamic contexts and resonates with Greenhalgh et al's (2019) recommendation to use a combination of implementation science's structured and phased approach, with the flexible and adaptive approach advocated by complexity science and an understanding of the social aspects of implementation (46). 
Contribution to the literature (to be added as a box in the discussion section):

- The focus of ExpandNet's 9 Step framework on vertical and horizontal scale-up helps guide planning and analysis of scale-up, although strategies should not be assumed to be linear 'steps'.

- Identifying priority system-level changes, e.g. to routine reporting and training, in partnership with health system actors was a prerequisite to institutionalisation of the intervention i.e. vertical scale-up.

- Use of insider-researchers, alliance-building, seizing opportunities for engagement in wider policy processes and building relationships with decisionmakers were effective tactics for embedding research.

- When dynamically applied, considering health system complexity, this embedded approach can increase intervention coverage i.e. horizontal scale-up.

Strengths and limitations: The short duration of the study limited our ability to follow up patients to identify the proportion of smokers who were abstinent at the six-month end of their TB treatment. Given the challenges of self-reported measures of cessation, biochemical validation of these quits would also have been necessary to assess the effectiveness of the scaled-up intervention within the learning sites (47). A further limitation was that estimated costs did not include administrative activities, small logistics items, overheads or salary on-costs which may vary across contexts and should be considered when budgeting for scale-up.

Our study has several strengths including the assessment of specific strategies in three different country contexts which included a range of public, private and NGO providers. The use of mix methods and the CFIR and Expandnet (20) framework helped to guide our analysis of the steps towards scale-up drawing on the multiple perspectives of implementation, complexity and social science.

\section{Conclusions}

Establishing a scale-up strategy which included a simplified and adaptable tobacco cessation intervention and prioritised health system changes to reporting forms, training and supervision was key to institutionalising cessation support for people with TB. Increasing coverage of the intervention was more challenging; this worked well when TB programme staff were also members of the research team and were embedded within the health system. While many scale-up frameworks are presented as a series of steps, we found a flexible and responsive approach with iterations between the steps was needed over a long time period. Following clear strategies to make changes to TB programmes can enable routine delivery of cessation support to TB patients. These strategies are inexpensive and, with concerted efforts from TB programmes and donor partners, tobacco cessation can be institutionalised and scaled up.

\section{Abbreviations}

CU: Common Unit for TB, HIV and Malaria, Government of Pakistan

CFIR: Consolidated Framework for Implementation Research

DP: Development Partners

GFTAM: Global Fund for TB, AIDS and Malaria

KP Province: Khyber Pakhtunkhwa Province, Pakistan

NCDC: Non-Communicable Disease Control department, Government of Bangladesh

NGO: Non-Governmental Organisation

NTP: National TB Programme

ToT: Training of trainers

TB: Tuberculosis

\section{Declarations}

Ethics approval and consent to participate: The study was conducted in accordance with the Helsinki Declaration (1964, revised 2013), and received ethical approval from the University of Leeds School of Medicine and Research Ethics Committee (SoMREC), Ref no: MREC 15-063. The study obtained ethical approval in all three countries where the study took place, from Nepal Health Research Council, Bangladesh Medical Research Council and the National BioEthics Committee Pakistan. All research participants provided written consent, and we have ensured confidentiality throughout the research and analysis process. Participants were provided with refreshments during interviews and focus groups and travel reimbursed, but no financial incentives were given.

Adherence to national and international regulations: Not applicable

Consent for publication: All participants provided consent for their anonymised data to be published. All data in this paper has been anonymised accordingly. 
Availability of data and materials: The data used and/or analysed during the current study are available from the corresponding author on reasonable request.

Competing interests: The authors declare that they have no competing interests.

Funding: TB\&Tobacco has received funding from the European Union's Horizon 2020 research and innovation programme under grant agreement No 680995. The funder has had no role in the design of the study and collection, analysis, and interpretation of data and in writing the manuscript.

Authors' contributions: HE, KS, SB, RH, RF were responsible for the development of the study concept. HE and JK drafted the manuscript. ZA and FF conducted and assisted with data collection and analysis in Bangladesh. AA, SR and PS conducted and assisted with data collection and analysis in Nepal. MN, ZK, SU, DMK and AK conducted and assisted with data collection and analysis in Pakistan. JL conducted the costing analysis. All authors were involved in revising the article critically for important intellectual content. Each author has been sufficiently involved in the work to take public responsibility for appropriate portions of the content and agree to be accountable for all aspects of the work in ensuring that questions related to the accuracy or integrity of any part of the work are appropriately investigated and resolved. All authors have read and approved the final manuscript.

Acknowledgements: The authors are grateful to the assistance and time research participants invested across the three countries and to other members of the TB and Tobacco consortium for their advice and insights.

\section{References}

1. Slama K, Chiang C-Y, Enarson DA, Hassmiller K, Fanning A, Gupta P, et al. Tobacco and tuberculosis: a qualitative systematic review and meta-analysis. Int J Tuberc Lung Dis [Internet]. 2007 Oct;11(10):1049-61. Available from: https://www.ncbi.nlm.nih.gov/pubmed/17945060.

2. Lin H-H, Ezzati M, Murray M. Tobacco smoke, indoor air pollution and tuberculosis: a systematic review and meta-analysis. PLoS Med [Internet]. 2007 Jan;4(1):e20. Available from: http://dx.doi.org/10.1371/journal.pmed.0040020.

3. Leung CC, Yew WW, Chan CK, Chang KC, Law WS, Lee SN, et al. Smoking adversely affects treatment response, outcome and relapse in tuberculosis. Eur Respir J [Internet]. 2015 Mar;45(3):738-45. Available from: http://dx.doi.org/10.1183/09031936.00114214.

4. Yen Y-F, Yen M-Y, Lin Y-S, Lin Y-P, Shih H-C, Li L-H, et al. Smoking increases risk of recurrence after successful anti-tuberculosis treatment: a populationbased study. Int J Tuberc Lung Dis [Internet]. 2014 Apr;18(4):492-8. Available from: http://dx.doi.org/10.5588/ijtld.13.0694.

5. Lönnroth K, Castro KG, Chakaya JM, Chauhan LS, Floyd K, Glaziou P, et al. Tuberculosis control and elimination 2010-50: cure, care, and social development. Lancet [Internet]. 2010 May 22;375(9728):1814-29. Available from: http://dx.doi.org/10.1016/S0140-6736(10)60483-7.

6. Siddiqi K, Khan A, Ahmad M, Dogar O, Kanaan M, Newell JN, et al. Action to Stop Smoking in Suspected Tuberculosis (ASSIST) in Pakistan. Ann Intern Med [Internet]. [cited 2020 Sep 18]; Available from: https://www.acpjournals.org/doi/10.7326/0003-4819-158-9-201305070-00006.

7. Dogar O, Keding A, Gabe R, Marshall A-M, Huque R, Barua D, et al. Cytisine for smoking cessation in patients with tuberculosis: a multicentre, randomised, double-blind, placebo-controlled phase 3 trial. Lancet Glob Health [Internet]. 2020 Nov;8(11):e1408-17. Available from: http://dx.doi.org/10.1016/S2214-109X(20)30312-0.

8. Siddiqi K, Keding A, Marshall A, Dogar O, Li J, Huque R, Fatima R, Khan A, Elsey H, Gabe R, Kotz D, Sheikh A. Do smokers with tuberculosis who quit smoking during treatment have better health outcomes than those who don't? A secondary analysis. Thorax. 2021.

9. Warsi S, Elsey H, Boeckmann M, Noor M, Khan A, Barua D, et al. Using behaviour change theory to train health workers on tobacco cessation support for tuberculosis patients: a mixed-methods study in Bangladesh, Nepal and Pakistan. BMC Health Serv Res [Internet]. 2019 Jan 25;19(1):71. Available from: https://doi.org/10.1186/s12913-019-3909-4.

10. WHO report on the global tobacco. epidemic 2019: offer help to quit tobacco use [Internet]. [cited 2020 Sep 18]. Available from: https://www.who.int/publications/i/item/who-report-on-the-global-tobacco-epidemic-2019-offer-help-to-quit-tobacco-use.

11. World Health Organization. WHO Report of the Global Tobacco Epidemic. Appendix 10.1 Comparable estimates of prevalence of tobacco use 2017 [Internet]. World Health Organization: Health Promotion. [cited 2021 Jan 20]. Available from: https://www.who.int/teams/health-promotion/tobaccocontrol/who-report-on-the-global-tobacco-epidemic-2019.

12. World Health Organisation. Country profiles for 30 high TB burden countries [Internet]. WHO TB Country Profiles. [cited 2018 Sep 20]. Available from: https://www.who.int/tb/publications/global_report/tb19_Report_country_profiles_150ctober2019.pdf?ua=1.

13. National Tuberculosis Control Centre, Ministry of Health and Population. NATIONAL TB PREVALENCE SURVEY. (2018-19) - FACTSHEET [Internet]. Government of Nepal; 2020. Available from: https://nepalntp.gov.np/wp-content/uploads/2020/03/TBPS-Factsheet-English.pdf.

14. Elsey H, Khanal S, Manandhar S, Sah D, Baral SC, Siddiqi K, et al. Understanding implementation and feasibility of tobacco cessation in routine primary care in Nepal: a mixed methods study. Implement Sci [Internet]. 2016 Jul 22;11:104. Available from: http://dx.doi.org/10.1186/s13012-016-0466-7.

15. Boeckmann M, Warsi S, Noor M, Dogar O, Mustagfira EH, Firoze F, et al. Health worker and patient views on implementation of smoking cessation in routine tuberculosis care. NPJ Prim Care Respir Med [Internet]. 2019 Sep 3;29(1):34. Available from: http://dx.doi.org/10.1038/s41533-019-0146-6.

16. Dogar O, Elsey H, Khanal S, Siddiqi K. Challenges of Integrating Tobacco Cessation Interventions in TB Programmes: Case Studies from Nepal and Pakistan. J Smok Cessat [Internet]. 2016 Jun [cited 2020 Sep 18];11(2):108-15. Available from: http://eprints.whiterose.ac.uk/95717/.

17. World Health Organisation. WHO | Fact sheet about health benefits of smoking cessation [Internet]. World Health Organization; 2013 [cited 2020 Sep 19]. Available from: https://www.who.int/tobacco/quitting/benefits/en/. 
18. Koorts H, Rutter H. A systems approach to scale-up for population health improvement. Health Res Policy Syst [Internet]. 2021 Mar 1;19(1):27. Available from: http://dx.doi.org/10.1186/s12961-021-00679-0.

19. Barker PM, Reid A, Schall MW. A framework for scaling up health interventions: lessons from large-scale improvement initiatives in Africa. Implement Sci [Internet]. 2016 Jan 29;11:12. Available from: http://dx.doi.org/10.1186/s13012-016-0374-x.

20. ExpandNet. Nine steps for developing a scalingup strategy [Internet]. World Health Organisation; 2010. Available from: https://www.who.int/immunization/hpv/deliver/nine_steps_for_developing_a_scalingup_strategy_who_2010.pdf.

21. Milat AJ, Bauman A, Redman S. Narrative review of models and success factors for scaling up public health interventions. Implement Sci [Internet]. 2015 Aug 12;10:113. Available from: http://dx.doi.org/10.1186/s13012-015-0301-6.

22. Callaghan-Koru JA, Islam M, Khan M, Sowe A, Islam J, Mannan II, et al. Factors that influence the scale up of new interventions in low-income settings: a qualitative case study of the introduction of chlorhexidine cleansing of the umbilical cord in Bangladesh. Health Policy Plan [Internet]. 2020 May 1;35(4):440-51. Available from: http://dx.doi.org/10.1093/heapol/czz156.

23. Ben Charif A, Zomahoun HTV, LeBlanc A, Langlois L, Wolfenden L, Yoong SL, et al. Effective strategies for scaling up evidence-based practices in primary care: a systematic review. Implement Sci [Internet]. 2017 Nov 22;12(1):139. Available from: http://dx.doi.org/10.1186/s13012-017-0672-y.

24. Michie S, et al. Behaviour Change Technique Online Training [Internet]. BCT Taxonomy v.1 Online Training. [cited 2021 Sep 20]. Available from: https://www.bct-taxonomy.com/.

25. Elsey H, Warsi S. Report of TB and Tobacco Project WP1: tobacco cessation intervention development [Internet]. University of Leeds; 2017. Available from: https://tbandtobacco.org/wp-content/uploads/sites/26/2019/05/WP1-Report-of-intervention-development.pdf.

26. Olivier J, Scott V, Molosiwa D, Gilson L. Systems approaches in health systems research:approaches for embedding research. In: De Savigny D, Blanchet K, Adam T, editors. Applied Systems Thinking for Health Systems Research: A methodological handbook. London: Open University; 2017. pp. 9-37.

27. WHO. Changing Mindsets: Strategy on Health Policy and Systems Research [Internet]. World Health Organization; 2012. Available from: https://apps.who.int/iris/bitstream/handle/10665/77942/9789241504409_eng.pdf.

28. WHO. Treatment of tuberculosis Guidelines Fourth edition [Internet]. World Health Organisation; 2010. Available from: https://apps.who.int/iris/bitstream/handle/10665/44165/9789241547833_eng.pdf;jsessionid=BADABC798C19143F159F68AF629E1F52?sequence=1.

29. Theobald S, Brandes N, Gyapong M, El-Saharty S, Proctor E, Diaz T, et al. Implementation research: new imperatives and opportunities in global health. Lancet [Internet]. 2018 Nov 17;392(10160):2214-28. Available from: http://dx.doi.org/10.1016/S0140-6736(18)32205-0.

30. Hong QN, Pluye P, Bujold M, Wassef M. Convergent and sequential synthesis designs: implications for conducting and reporting systematic reviews of qualitative and quantitative evidence. Syst Rev [Internet]. 2017 Mar 23;6(1):61. Available from: http://dx.doi.org/10.1186/s13643-017-0454-2.

31. Fiedler JL, Villalobos CA, De Mattos AC. An activity-based cost analysis of the Honduras community-based, integrated child care (AIN-C) programme. Health Policy Plan [Internet]. 2008 Nov;23(6):408-27. Available from: http://dx.doi.org/10.1093/heapol/czn018.

32. Malterud K, Siersma VD, Guassora AD. Sample Size in Qualitative Interview Studies: Guided by Information Power. Qual Health Res [Internet]. 2016 Nov;26(13):1753-60. Available from: http://dx.doi.org/10.1177/1049732315617444.

33. Damschroder LJ, Aron DC, Keith RE, Kirsh SR, Alexander JA, Lowery JC. Fostering implementation of health services research findings into practice: a consolidated framework for advancing implementation science. Implement Sci [Internet]. 2009 Aug 7;4:50. Available from:

http://dx.doi.org/10.1186/1748-5908-4-50.

34. Gale NK, Heath G, Cameron E, Rashid S, Redwood S. Using the framework method for the analysis of qualitative data in multi-disciplinary health research. BMC Med Res Methodol [Internet]. 2013 Sep 18;13:117. Available from: http://dx.doi.org/10.1186/1471-2288-13-117.

35. Pinnock H, Barwick M, Carpenter CR, Eldridge S, Grandes G, Griffiths CJ, et al. Standards for Reporting Implementation Studies (StaRI) Statement. BMJ [Internet]. 2017 Mar 6;356:i6795. Available from: http://dx.doi.org/10.1136/bmj.i6795.

36. National TB, Centre. Ministry of Health. National Strategic Plan For Tuberculosis Prevention, Care And Control 2016-2021 [Internet]. Government of Nepal; 2016. Available from: https://nepalntp.gov.np/wp-content/uploads/2018/01/NSP-report-english-revised.pdf.

37. Harries AD, Zachariah R, Jahn A, Schouten EJ, Kamoto K. Scaling up antiretroviral therapy in Malawi-implications for managing other chronic diseases in resource-limited countries. J Acquir Immune Defic Syndr [Internet]. 2009 Nov;52 Suppl 1:S14-6. Available from: http://dx.doi.org/10.1097/QAI.0b013e3181bbc99e.

38. Yamey G. Scaling up global health interventions: a proposed framework for success. PLoS Med [Internet]. 2011 Jun;8(6):e1001049. Available from: http://dx.doi.org/10.1371/journal.pmed.1001049.

39. Chambers DA, Glasgow RE, Stange KC. The dynamic sustainability framework: addressing the paradox of sustainment amid ongoing change. Implement Sci [Internet]. 2013 Oct 2;8:117. Available from: http://dx.doi.org/10.1186/1748-5908-8-117.

40. Wiltsey Stirman S, Kimberly J, Cook N, Calloway A, Castro F, Charns M. The sustainability of new programs and innovations: a review of the empirical literature and recommendations for future research. Implement Sci [Internet]. 2012 Mar 14;7:17. Available from: http://dx.doi.org/10.1186/1748-5908-717.

41. Rogers EM. Diffusion of Innovation [Internet]. 4th ed. The Free Press; 1995. 536 p. Available from: https://www.amazon.co.uk/Diffusion-InnovationEverett-M-Rogers/dp/0029266718.

42. Wyatt J, Spiegelhalter D. Field trials of medical decision-aids: potential problems and solutions. Proc Annu Symp Comput Appl Med Care [Internet]. 1991;3-7. Available from: https://www.ncbi.nlm.nih.gov/pubmed/1807610. 
43. Dückers ML, Wagner C, Vos L, Groenewegen PP. Understanding organisational development, sustainability, and diffusion of innovations within hospitals participating in a multilevel quality collaborative. Implement Sci [Internet]. 2011 Mar 9;6:18. Available from: http://dx.doi.org/10.1186/1748-5908-6-18.

44. Milat AJ, King L, Newson R, Wolfenden L, Rissel C, Bauman A, et al. Increasing the scale and adoption of population health interventions: experiences and perspectives of policy makers, practitioners, and researchers. Health Res Policy Syst [Internet]. 2014 Apr 15;12:18. Available from: http://dx.doi.org/10.1186/1478-4505-12-18.

45. Weible CM, Heikkila T, deLeon P, Sabatier PA. Understanding and influencing the policy process. Policy Sci [Internet]. 2012 Mar 1;45(1):1-21. Available from: https://doi.org/10.1007/s11077-011-9143-5.

46. Greenhalgh T, Papoutsi C. Spreading and scaling up innovation and improvement. BMJ [Internet]. 2019 May 10;365:I2068. Available from: http://dx.doi.org/10.1136/bmj.I2068.

47. West R, Hajek P, Stead L, Stapleton J. Outcome criteria in smoking cessation trials: proposal for a common standard. Addiction [Internet]. 2005 Mar;100(3):299-303. Available from: http://dx.doi.org/10.1111/j.1360-0443.2004.00995.x.

48. Dogar O, Barua D, Boeckmann M, Elsey H, Fatima R, Gabe R, et al. The safety, effectiveness and cost-effectiveness of cytisine in achieving six-month continuous smoking abstinence in tuberculosis patients-protocol for a double-blind, placebo-controlled randomized trial. Addiction [Internet]. 2018 Apr 20; Available from: http://dx.doi.org/10.1111/add.14242.

\section{Figures}

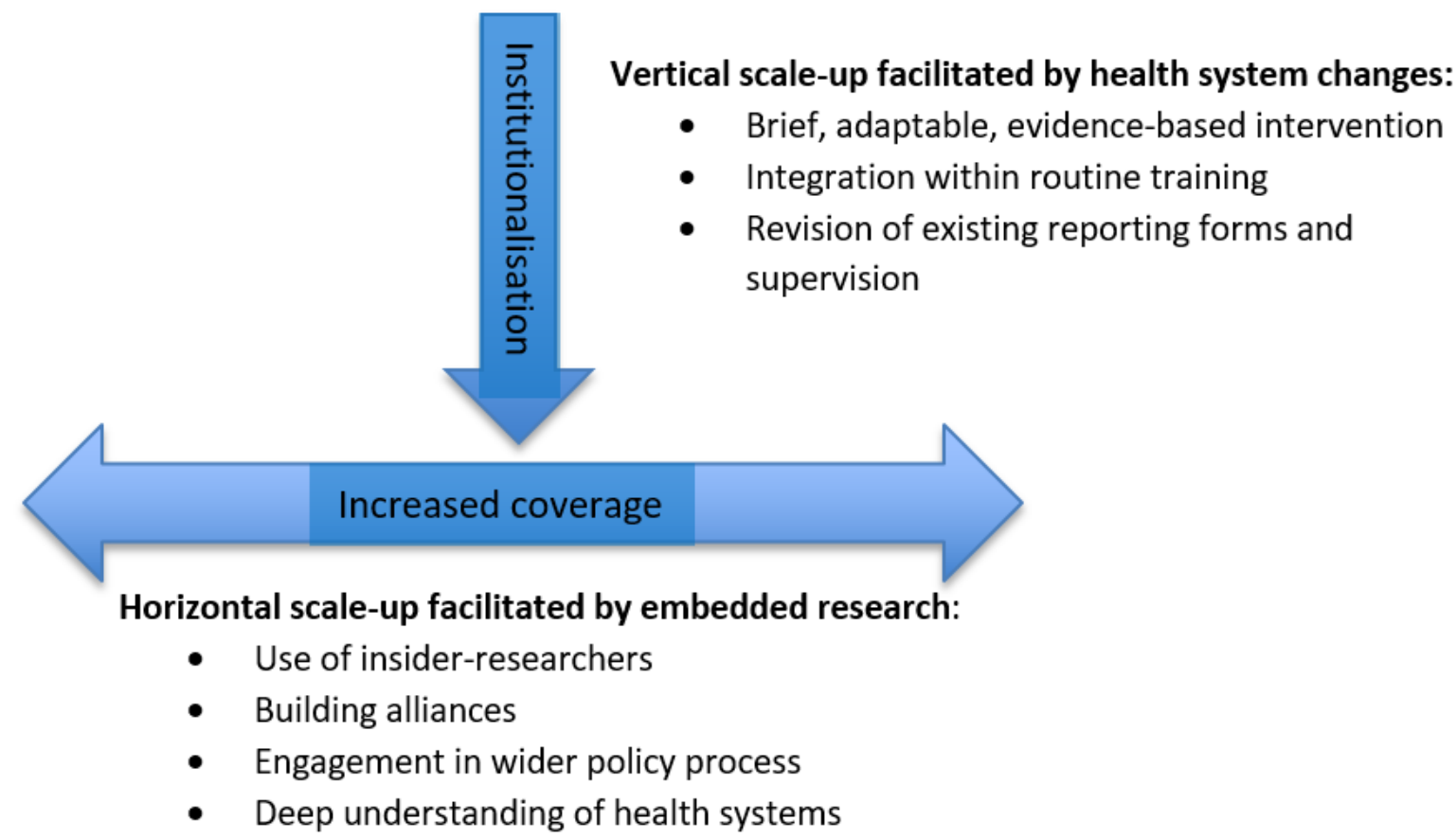

Figure 1

Strategies to support vertical and horizontal scale-up

\section{Supplementary Files}

This is a list of supplementary files associated with this preprint. Click to download.

- StaRIchecklistTBTobaccoWP6.docx 